\title{
THE COURSE OF PRIMARY INFECTION WITH NECATOR AMERICANUS IN SYNGENEIC MICE
}

\author{
Catherine Wells and Jerzy M. Behnie* \\ MRC Experimental Parasitology Research Group, Department of Zoology, University of Nottingham, University Park, \\ Nottingham NG7 2RD, U.K.
}

\author{
(Received 9 March 1987)
}

\begin{abstract}
Wells C. and Behnke J. M. 1988. The course of primary infection with Necatoramericanus in syngeneic mice. Intemational Joumal for Parasitology 18:47-51. A panel of syngeneic mouse strains was compared for susceptibility to infection with a hamster adapted strain of $N$. americanus. Lung worm burdens were compared 4-5 days after percutaneous exposure to 190-375 larvae. SJL and DBA/1 were most susceptible. Balb/c, DBA/2 and CBA strains showed intermediate worm burdens and $S W R, \mathrm{C}_{57} \mathrm{BL}_{3 \cdots}$ $\mathrm{NIH}$ and $\mathrm{C} 3 \mathrm{H} / \mathrm{HR}$ mice were the most resistant. NIH and Balb/c mice consistently showed significant differences in lung worm establishment and were selected for closer examination. The recovery of larvae from the skin on day 2 and the subsequent rate of loss from this site were similar in both strains. However, Balb/c mice developed significantly higher lung worm burden than NIH and the rate of loss from the lung was more rapid. $L_{4}$ larvae were first recovered from the small intestines of Balb/c mice on day 7 , numbers reaching a peak on day 9 when the mean intestinal recovery corresponded to $10 \%$ of the peak lung burden. Intestinal stages were not found in NIH mice and no larvae were found in other tissue sites of either strain. The relevance of $N$. americanus in mice as a model for the study of host-parasite relationships of the invasive and migratory stages of hookworms is discussed.
\end{abstract}

INDEX KEY WORDS: Necator americanus; hookworms; Mus musculus; mouse strains; skin; lungs; intestine.

\section{INTRODUCTION}

HUMAN hookworm infection remains a major cause of morbidity in tropical and sub-tropical regions of the world despite the development of effective anthelmintics. The lack of suitable laboratory models for hookworm disease has undoubtedly hindered experimental studies of the host-parasite relationship. Both Necator americanus and Ancylostoma duodenale are anthropophilic in contrast to the third species infecting man, A. ceylanicum, which also occurs in dogs and cats. There are a number of hookworm species closely related to Ancylostoma duodenale which have been used extensively for both immunological and non-immunological studies (e.g. A. caninum in dogs and $A$. tubaeformae in cats); on the other hand, there are no hookworm species closely related to $N$. americanus which can be conveniently studied in laboratory systems. Attempts to infect laboratory animals with $N$. americanus have been reported and have included guinea-pigs, hamsters, mice, dogs, rabbits, rats and various primates. However, chronic infections paralleling those seen in humans have only been consistently achieved in neonatally infected rabbits and hamsters (Yoshida \& Fukutome, 1967; Sen \& Seth, 1970; Sen, 1972). The hamster in particular has been exploited for maintaining the parasite in the

\footnotetext{
* Author to whom correspondence should be addressed.
}

laboratory and providing the life cycle stages obtainable only with difficulty from man (Behnke, Paul \& Rajasekariah, 1986; Pritchard, Behnke, Carr \& Wells, 1986).

Although adult $N$.americanus have been recovered from mice treated with massive doses of egg albumin (Lancastre, Bazin, Golvan, Deltour, Mougeot \& Houin, 1969) N. americanus does not normally develop to maturity in the intestines of this host (Nichols, 1956; Soh, 1958; Ray, Bophale \& Shrivastava, 1975).

Nevertheless, infections in mice do provide an opportunity to study the invasive and migratory stages of the parasite. Unlike neonatal hamsters and rabbits, adult mice are fully immunocompetent and can be manipulated easily in the laboratory by well established techniques. In this paper we describe experiments undertaken to evaluate $N$. americanus in the mouse as a system for studying the early stages of hookworm development and define aspects of the host-parasite relationship which are unavailable from studies of neonatally administered infections in hamsters and rabbits.

\section{MATERIALS AND METHODS}

Mice were either bred and maintained under conventional animal house conditions (Balb/c, NIH, SJL, SWR, $\mathrm{C}_{57} \mathrm{BL}_{101}$, CBA) or obtained from OLAC Ltd (DBA $/ 1, \mathrm{DBA} / 2, \mathrm{C} 3 \mathrm{H} /$ 
HR) and similarly maintained in the Department of Zoology, Nottingham University. All mice were given water and food ad libitum and were infected at 6-8 weeks of age. Experimental groups comprised five to nine animals. Infective larvae of a hamster-adapted strain of Necator americanus were obtained from Dr. G. Rajasakariah of Hindustan CIBA-GEIGY Ltd, Bombay, India. The parasite was maintained in Nottingham by serial passage through neonatal hamsters. Mice were infected percutaneously as described by Behnke, Wells \& Brown (1986). Briefly, mice were anaesthetized with Saggital $(\mathrm{M}+\mathrm{B}$ Veterinary Products). The abdomen was shaved, cleaned and the appropriate dose of larvae was administered on a gauze and secured on the skin with adhesive tape for $24 \mathrm{~h}$.

Assessment of worm numbers was made by enumeration of larvae capable of active migration from the tissues, as described by Behnke et al.(1986). The animals were killed by inhalation of chloroform and the abdominal skin, lungs and small intestine were removed. The skin and lungs were minced with scissors and incubated in $5 \mathrm{~cm}$ Petri dishes containing Hanks' saline. The dishes were incubated at $37^{\circ} \mathrm{C}$ and larvae migrating from the tissues were recovered after 2 , 6 and $24 \mathrm{~h}$. The small intestine was split longitudinally and placed on a piece of gauze which was suspended in a $50 \mathrm{ml}$ beaker containing Ilanks' saline and incubated for $6 \mathrm{~h}$ at $37^{\circ} \mathrm{C}$. The larvae were collected after sedimentation.

Statistical significance of the results was determined by use of the Mann-Whitney $U$-test (Sokal \& Rohlf. 1969) to compare experimental groups, a value of $P<0.05$ being considered significant.

\section{RESULTS}

Comparison of mouse strains and sexes by lung worm recovery 4 or 5 days post-infection

Parasite establishment in the lungs was assessed by recovery from this site 4 or 5 days post-infection, in nine inbred strains of mice. It can be seen from the data presented in Table 1 that significant differences occurred between certain strains. Balb/c mice were used as the reference strain throughout the seven experiments, and on this basis the strains tested can be divided into three groups: SJL, DBA $/ 1>\mathrm{Balb} / \mathrm{c}$. $\mathrm{DBA} / 2, \mathrm{CBA}>\mathrm{SWR}, \mathrm{C}_{57} \mathrm{~B} / 10, \mathrm{NIH}, \mathrm{C} 3 \mathrm{H} / \mathrm{HR}(>$ denoting a significant difference in worm recovery).

No differences were observed when the worm burdens were compared in male vs. female NIH or Balb/c mice (Expts. 4 and 5). However, whereas male $\mathrm{C}_{57} \mathrm{BL}_{10}$ mice were significantly more resistant than male Balb/c (Expt. 1) the worm recoveries from the females of these strains did not differ significantly (Expts. 4,6 and 7).

\section{Time course of infection in male Balb/c mice}

Twenty-four hours after infection $68 \%$ of the administered dose was recovered from the skin site. Worm recovery from the skin thereafter declined to $<40 \%$ by day 3 and by 5 days post-infection no larvae could be recovered (Fig. 1).

TABLE 1-COMPARISON OF INITIAL ESTABLISHMENT IN DIFFERENT MOUSE STRAINS

\begin{tabular}{|c|c|c|c|c|c|c|c|}
\hline Experiment & Dose & Sex & Strain & $\begin{array}{l}\text { Mean worm } \\
\text { recovery on } \\
\text { day } 5 \pm \text { S.E.M. }\end{array}$ & $n$ & \multicolumn{2}{|c|}{$\begin{array}{l}\text { Statistical } \\
\text { analysis: } \\
P \text { value }\end{array}$} \\
\hline 1 & 375 & $\begin{array}{l}0 \\
0 \\
0\end{array}$ & $\begin{array}{l}\mathrm{C}_{57} \mathrm{BL}_{11} \\
\mathrm{NIH} \\
\mathrm{Balb} / \mathrm{C}\end{array}$ & $\begin{aligned} 36.5 & \pm 10.4 \\
47.25 & \pm 9.0 \\
120.75 & \pm 30.3\end{aligned}$ & $\begin{array}{l}8 \\
8 \\
8\end{array}$ & $\begin{array}{l}<0.001 \\
<0.05\end{array}$ & \\
\hline 2 & 200 & $\begin{array}{l}0 \\
0 \\
0 \\
0\end{array}$ & $\begin{array}{l}\mathrm{Balb} / \mathrm{c} \\
\mathrm{SWR} \\
\mathrm{C} 3 \mathrm{H} / \mathrm{HR} \\
\mathrm{DBA} / 2\end{array}$ & $\begin{array}{l}59.8 \pm 7.9 \\
21.5 \pm 4.5 \\
36.3 \pm 9.9 \\
50.0 \pm 4.3\end{array}$ & $\begin{array}{l}5 \\
6 \\
6 \\
6\end{array}$ & $\begin{array}{c}<0.025 \\
<0.01 \\
\text { n.s. }{ }^{*}\end{array}$ & \\
\hline 3 & 200 & $\begin{array}{l}0 \\
0 \\
0\end{array}$ & $\begin{array}{l}\text { Balb/c } \\
\mathrm{SJL} \\
\mathrm{DBA} / 1\end{array}$ & $\begin{array}{l}64.0 \pm 4.65 \\
81.5 \pm 6.3 \\
86.7 \pm 6.6\end{array}$ & $\begin{array}{l}5 \\
8 \\
7\end{array}$ & $\begin{array}{l}<0.00 .5 \\
<0.01\end{array}$ & \\
\hline 4 & 190 & $\begin{array}{l}0 \\
0 \\
0 \\
0 \\
0\end{array}$ & $\begin{array}{l}\mathrm{CBA} \\
\mathrm{NIH} \\
\mathrm{Balb} / \mathrm{c} \\
\mathrm{Balb} / \mathrm{c} \\
\mathrm{C}_{57} \mathrm{BL}_{11}\end{array}$ & $\begin{array}{l}89.3 \pm 16.3 \\
44.6 \pm 5.96 \\
81.9 \pm 10.6 \\
63.1 \pm 4.5 \\
55.0 \pm 8.7\end{array}$ & $\begin{array}{l}8 \\
8 \\
8 \\
8 \\
8\end{array}$ & $\begin{array}{c}\text { n.s. } \\
<0.005 \\
\text { n.s. } \\
<0.05\end{array}$ & n.s. \\
\hline 5 & 190 & $\begin{array}{l}0 \\
q\end{array}$ & $\begin{array}{l}\mathrm{NIH} \\
\mathrm{NIH}\end{array}$ & $\begin{array}{l}38.0 \pm 4.30 \\
33.2 \pm 5.46\end{array}$ & $\begin{array}{l}5 \\
5\end{array}$ & n.s. & \\
\hline 6 & 250 & $\begin{array}{l}q \\
q\end{array}$ & $\begin{array}{l}\mathrm{Balb} / \mathrm{c} \\
\mathrm{C}_{57} \mathrm{BL}_{11}\end{array}$ & $\begin{array}{l}75.2+4.4 \\
76.0 \pm 20.2\end{array}$ & $\begin{array}{l}5 \\
5\end{array}$ & n.s & \\
\hline 7 & 190 & $\begin{array}{l}q \\
q\end{array}$ & $\begin{array}{l}\mathrm{Balb} / \mathrm{c} \\
\mathrm{C}_{57} \mathrm{BL}_{113}\end{array}$ & $\begin{array}{l}48.6 \pm 14.2 \\
57.8 \pm 14.7\end{array}$ & $\begin{array}{l}5 \\
6\end{array}$ & $n s$. & \\
\hline
\end{tabular}

* n.s., not significantly different. 


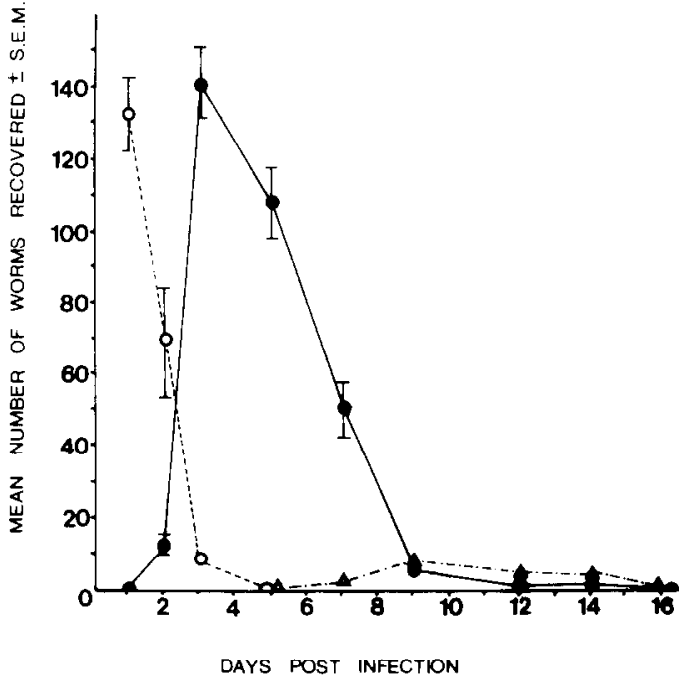

FIG. 1. Time course of $N$. americanus infection in male Balb/c mice. 0 , Skin recovery; $\bullet$, lung recovery; $\triangle$, gut recovery.

Larvae were first observed in the lungs on day 2, when approx. $6 \%$ of the administered dose was recovered. A rapid increase in the recovery of the pulmonary stages followed, coinciding with a comparable loss from the skin. Peak worm counts from the lungs were recorded on day 3 when $72 \%$ of the infecting dose was recovered from this site. From day 5 lung recoveries began a steady decline. Worms were first recovered from the small intestine on day 7 , reaching a peak on day 9 (approx. $4 \%$ of the administered dose). Sixteen days post-infection no worms could be recovered from either site. The small number of worms recovered from the intestine comprised L4 stages in which limited growth had taken place. No adult worms were observed.
Comparison of the time course of infection in male $\mathrm{Balb} / \mathrm{c}$ and NIH mice

The time course of pulmonary migration was compared in two strains Balb/c and NIH, identified from our initial studies as being relatively susceptible and resistant respectively. The results in Table 2 show considerable differences between these strains in parasite migration through the lung and subsequent appearance in the intestine.

The recovery of larvae from the skin on day 2 and the rate of loss from this site were found to be similar in both strains, thus in Balb/c mice the lung worm burden on day 3 represented $70 \%$ of the mean skin recovery $24 \mathrm{~h}$ earlier, and $76 \%$ in NIH mice. However, significantly fewer worms were recovered from the lungs of NIH mice on day $5(P<0.025)$. The rate of larval loss from the lungs also differed between the strains. In NIH mice $42 \%$ of the peak lung recovery (day 3 ) persisted in the lungs until day 9 , compared to $9 \%$ in Balb/c's. Fourth stage larvae were recovered from the intestines of $\mathrm{Balb} / \mathrm{c}$ mice from day 7 peaking on day 9 (approx. $10 \%$ of maximum lung values). In contrast only two worms were isolated on day 9 from $2 \mathrm{NIH}$ mice. Other tissue sites such as the liver and selected musculature (stripped from either side of the spine and surrounding the upper hind limbs) were also examined. No larvae were recovered from these sites in either strain on days 5 or 9 post-infection.

\section{DISCUSSION}

Necator americanus is essentially an anthropophilic nematode with only partially successful development in host species other than man. As yet there are no animal models of necatoriasis that fulfil the criteria described by Carroll and Grove (1984) as required for a valid experimental model of hookworm disease.

The major pathologies of human hookworm infection are generally attributed to the haematophagous feeding activities of the adult worms resident in the

Table 2-Time course of migration in ơ NIH and Balb/c mice

\begin{tabular}{|c|c|c|c|c|c|c|c|c|}
\hline \multirow{3}{*}{$\begin{array}{l}\text { Experi- } \\
\text { ment }\end{array}$} & \multirow{3}{*}{$\begin{array}{l}\text { Day } \\
\text { PI }\end{array}$} & \multicolumn{6}{|c|}{ Mean worm recovery \pm S.E.M } & \multirow{3}{*}{$\begin{array}{l}\mathrm{d} 9 / \mathrm{d} 5 \text { lung } \\
\mathrm{WK} \times 100\end{array}$} \\
\hline & & \multicolumn{2}{|c|}{ Skin } & \multicolumn{2}{|c|}{ Lungs } & \multicolumn{2}{|r|}{ Gut } & \\
\hline & & NIH & $\mathrm{Balb} / \mathrm{c}$ & NIH & $\mathrm{Balb} / \mathrm{c}$ & $\mathrm{NIH}$ & $\mathrm{Balb} / \mathrm{c}$ & \\
\hline \multirow[t]{5}{*}{1} & 2 & $51.0 \pm 15.68$ & $60.0 \pm 10.34$ & 1 & $2.0 \pm 1.08$ & n.d. & n.d. & \multirow{3}{*}{$\mathrm{NIH}: 42.97$} \\
\hline & 3 & $4.0 \pm 1.16$ & $5.25 \pm 0.75$ & $66.75 \pm 2.66$ & $85.5 \pm 9.21$ & n.d. & n.d. & \\
\hline & 5 & 0.0 & 0.0 & $65.75 \pm 9.48$ & $112.75 \pm 9.79$ & 0.0 & 0.0 & \\
\hline & 7 & n.d. & n.d. & $53.0 \pm 2.86$ & $71.0 \pm 5.0$ & 0.0 & 1 & Balb/c: 8.58 \\
\hline & 9 & n.d. & n.d. & $28.85 \pm 5.65$ & $9.67 \pm 2.52$ & 1 & $11.0 \pm 3.5$ & \\
\hline \multirow[t]{3}{*}{2} & 9 & n.d. & n.d. & n.d. & n.d. & 1 & $12.6 \pm 3.78$ & \\
\hline & 13 & n.d. & n.d. & n.d. & n.d. & 0.0 & $8.8 \pm 3.99$ & \\
\hline & 16 & n.d. & n.d. & n.d. & n.d. & 0.0 & 1 & \\
\hline
\end{tabular}

PI, post infection; WR, worm recovery.

* Ratio indicating the proportion of larvae remaining in the lung on day $9 \mathrm{PI}$. 
small intestine. Furthermore, larval hookworms also produce clinical pathologies during skin penetration, for example "ground itch" (Miller, 1979), and cutaneous larval migrans is recognized as indicating exposure to non-human species such as $A$, brasiliense (see Beaver, 1956). Subsequent development and migration through the lungs of $N$. americanus and A. duodenale in humans may result in a spectrum of pulmonary symptoms (reviewed by Miller, 1979; Banwell \& Schad, 1978) including bronchitis, pneumonitis and eosinophilia. The host-parasite relationship of adult worms can be studied following infection of neonatal hamsters and rabbits in which chronic infections develop approximating those in the definitive host. The immunological immaturity of the neonatal models during the early infection precludes the study of immunological aspects of the hostparasite relationship during initial invasion and migration. However, the results presented in this paper demonstrate that the adult mouse may be of value for the study of such stages.

Consistent and significant differences in the susceptibility to initial establishment of $N$. Americanus in the mouse lung occurred among the nine strains which were examined. Epidemiological studies (Schad \& Anderson, 1985) now indicate that predisposition to infection can occur in certain endemic regions. This is undoubtedly multifactorial in origin but it is likely that genetic and immunological factors are involved. The isolation of the most important determinants of resistance is extremely difficult under field conditions. However, the range of inbred mouse strains available should enable the definition of genetic factors in controlling innate and immunological resistance to the invasive and pulmonary stages of $N$. americanus in this model, providing a useful foundation for the interpretation of data from field studies in endemic regions.

Visceral migration of Ancylostoma spp. larvae are common in the definitive hosts, unlike $N$. americanus, and the species which have been studied in rodents also migrate to various tissue sites besides the lung (Matsuaki, 1951; Nichols, 1956; Bhopale \& Johri, 1975; Carroll, Grove, Hawkins, Mitchell \& Whitten, 1983 ). In contrast the course of skin and subsequent pulmonary migration of our hamster adapted strain of $N$. americamus in the adult mouse followed what appeared to be a direct and simple migration route, thus enabling the accurate quantification of worm burdens in the skin, lungs and intestine during the course of infection. Our observations contrast with those of an earlier study by Soh (1958) who found that $N$. americanus larvae persisted in murine muscle up to 30 days post-infection. The use of our hamster adapted strain of this parasite compared with infective larvae derived from human faeces possibly accounts for the more precise migration pattern observed by us, and a closer approximation to the human condition.

In addition to differential lung parasite establishment in strains identified as resistant or susceptible
( $\mathrm{NIH}$ and Balb/c respectively), differences in subsequent pulmonary migration kinetics were also detected. The time course of worm loss from the skin site was similar in both strains and thus it would appear unlikely that the prolonged lung recovery in NIH mice is due to slower passage through the skin. Rather it may result from different conditions within the lungs themselves.

Studies on A. caninum in dogs (Miller, 1965) have indicated the lung as being a major site in the acquisition and possibly also in the expression of acquired resistance to reinfection. The $N$. americanus-mouse model described here may thus prove to be a useful system in which to study pulmonary immunity to this parasite without the complications of neonatal unresponsiveness and larval stages concurrently residing in other tissue sites. Additionally, with the availability of syngeneic mouse strains it should be possible to dissect the mechanisms of resistance to $N$. americanus larvae, both innate and acquired, operating at consecutive stages during skin penetration, migration and residence in the lungs.

Acknowledgements - We would like to thank Professors D. Wakelin and P.N.R. Usherwood for providing the facilities for this work at Nottingham University. CW was supported by a postgraduate sudentship from SERC. and IMB would like to acknowledge the MRC for generous financial support. Thanks are also due to Mrs. J. Brown for technical assistance, Mr. K. Cosgrove for maintenance of the experimental animals and Miss W. M. Lister for typing the manuscript.

\section{REFERENCES}

BANwELI. G. \& SCHAD G. A. 1978. Hookworm. Clinics in Gastroenterology 7: 129-156.

Beaver P. C. 1956. Larva migrans. A review. Experimental Parasitology 5: 587621 .

Behnke J. M., Paul. V. \& Rajasekarlah G. R. 1986. The growth and migration of Necator americants following infection of neonatal hamsters. Transactions of the Roval Society of Tropical Medicine and Hygiene 80: 146-149.

Behnke J. M., Wells C. \& Brown J. 1986. An improved technique for experimental infections with skin penetrating nematode larvae (Necator americanus). Expenmentat Parasitology 16: 461-464.

Borhale M.K.\& Johri G. N. 1975. Experimental infection of Ancylostoma caninum in mice. II. Migration and distribution of larvae in the tissues after oral infection. Journal of Helminthology 49: 179-185.

Carroll S. M., Grove D. I., Hawkins H. J. S., Mitchel.t. G. F. \& Whitres L. K. 1983. Infections with a Malaysian dog strain of Ancylostoma ceylantcum in outbred, inbred and immunocompromised mice. Parasitology 87:229238 .

Carroll S.M.\& Grove D.1. 1984. Parasitological, haematologic and immunologic responses in acute infections of dogs with Ancylostoma ceylanicum: a model of human hookworm infection. Journal of Infectious Diseases 150: 284-294. 


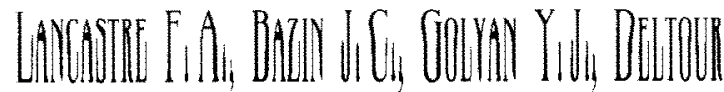

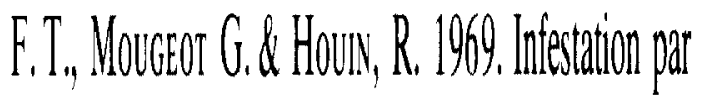

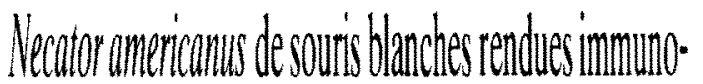

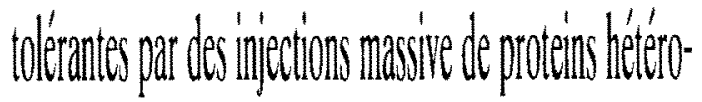

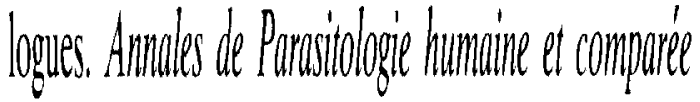
4(1. $241-240$

Matsuaki G. 1951. Studies on the life history of the hookworm. 7. On the development of Ancylostoma caninum in abnormal host. Yokohama Medical Bulletin 2: $154-160$.

MiLleR, T. A. 1965. Effect of route of administration of vaccine and challenge on the immunogenic efficiency of double vaccination with irradiated Ancylostoma caninum larvae. Journal of Parasitology 51: 200-206.

Miller T. A. 1979. Hookworm infection in man. Advances in Parasitology 17: 315-353.

NichoLs R. L. 1956. The etiology of visceral larva migrans. II. Comparative larval morphology of Ascaris lumbricoides, Necator americanus, Strongyloides stercoralis and Ancylostoma caninum. Journal of Parasitology 42: 363399.

Pritchard D. I., Beimke J. M., Carr A. \& Wells C. 1986. The recognition of antigens on the surface of adult and L4

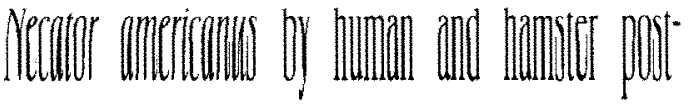
infection serta. Pandosite Immmunoloy 8.327-335.

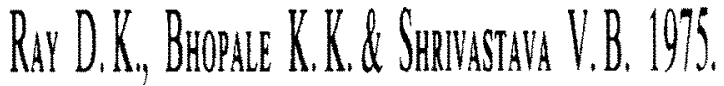

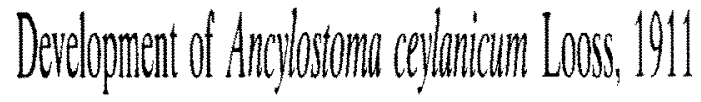

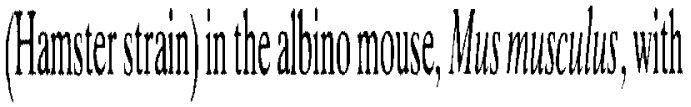
and without cortisone. Parnsitidogy $71: 193-199$.

Schad G. A. \& Anderson R. M. 1985. Predisposition to hookworm infection in humans. Science 228: 15371540.

SEN H.G. \& S Sth D. 1970. Development of Necator americanus in golden hamsters, Mesocricetus auratus. Indian Journal of Medical Research 58: 1356-1360.

SEN H. G. 1972. Necator americanus: behaviour in hamsters. Experimental Parasitology 32: 26-32.

$\mathrm{SoH}$ C. T. 1958. The distribution and persistence of hookworm larvae in the tissues of mice in relation to species and routes of inoculation. Journal of Parasitology 44: $515-519$.

Sokal R. R. \& Rolf F. 3. Biometry. W. H. Fueeman, San Francisco.

Yoshida Y.\& Fukutome S. 1967. Experimental infection of rabbits with the hookworm Necator americanus. Journal of Parasitology 53: 1067-1074. 